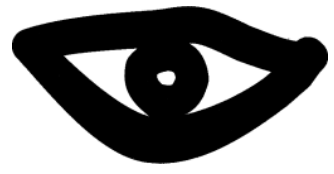

\title{
A cantar, dançar, escutar, jogar e a ler conseguimos aprender música
}

\author{
Marta Garcia Tracana \\ ESE Jean Piaget; Vila Nova de Gaia - Portugal
}

\begin{abstract}
Resumo
O ensino da Música para crianças pequenas, em Portugal, tem apresentado um enorme relevo para a formação global da criança. Utilizando como ferramentas de apoio histórias infantis, a Musicflat elaborou um plano de intervenção e criação musical assente na componente performativa das artes, aliando a música ao movimento e ao canto. A criação de workshop levaram o corpo docente a implementar estratégias educativas muito próprias, desenvolvendo e construindo competências musicais apropriadas às faixas etárias, adequadas ao desenvolvimento cognitivo, motor e psicológico da criança, tal como defendem Paynter, Swanwick, Schafer, Mills, Willems, Hargreaves.

Palavras chave: educação musical, prática musical, iniciação musical, pedagogia
\end{abstract}

\section{O ensino da música para crianças em Portugal}

Estudos feitos recentemente por Tracana (2013) sobre o ensino da música, estudo de caso múltiplo, centrado no ensino para crianças pequenas (dos 6 aos 10 anos, equivalente ao $1 .^{\circ}$ ciclo do ensino básico), mostra um exemplo daquilo que se passa em Portugal. Por um lado, no ensino genérico, a expressão musical é a disciplina que está sobre a responsabilidade do professor monodocente, cujos conhecimentos científicos musicais não são capazes de dar resposta ao que é pedido nos programas curriculares e às diretrizes emanadas por organismos internacionais sobre aquilo que deve ser ensinado a crianças. Por outro lado, no ensino especializado, a disciplina de iniciação musical sofre as consequências de não ter regulamentação por parte da tutela: diversidade na formação dos professores e disparidade dos programas curriculares da disciplina consoante os diferentes projetos educativos das escolas. Em ambos os casos a falta de conhecimento e de formação na área do ensino e da educação musical em estudos da criança é notória e origina muitas lacunas.

\section{O despertar de novas formas de ensinar música}

Há já alguns anos que vários espaços de ensino de atividades musicais têm pensado em novas estratégias para ensinar música, vendo a relação da criança com a música uma forma de a educar como um todo e não apostar apenas nas suas aptidões musicais, pois, segundo Mills e Paynter (2008, p. 4) "education (...) should be child-centred and start from the needs of the individual."

Muitos são os exemplos que apostaram na criação espaços de desenvolvimento e aprendizagem musical assentes nos princípios das pedagogias modernas, onde o movimento, a percepção sensorial, a criatividade, o jogo, são a base de toda a planificação da atividade musical.

Verificando as falhas do ensino genérico e as disparidades aos mais variados níveis do ensino especializado, a equipa de docentes da Musicflat elaborou o seu plano educativo sobre os pilares dos princípios pedagógicos que englobam, não só a literacia e cientificidade da música, mas também a componente lúdica, cujo papel para a aprendizagem musical é preponderante, assente no movimento, no canto e na audição ativa, no teatro musical e no jogo.

O movimento na aprendizagem musical. "La música es un arte del movimiento; acontece en el tiempo al igual de la danza y la poesía. Estas tres artes están íntimamente unidas en el ritmo. Se diferenciarán según la materia prima utilizada: el sonido para la música, el cuerpo humano para la danza y las palabras para la poesía.” (Willems, 1994, p. 29).

Como afirmou Willems, a relação da música com movimento é algo que acontece naturalmente. $\mathrm{O}$ ritmo está associado a diferentes aspetos da vida quotidiana: no trabalho onde a motricidade é essencial para o desempenho profissional, a utilização de padrões rítmicos para executar os trabalhos é bastante frequentes; no desporto, os atletas marcam o seu tempo para poderem desempenhar as suas tarefas numa pulsação certa, elevando o índice de resistência física, podendo mesmo utilizar música para o fazer; numa viagem, somos levados a ouvir música para melhor realizarmos o passeio.

A relação da música e a criança é linear: para uma criança associar gestos, mímica, movimento a uma canção fá-la-á compreender conceitos elementares da música como a pulsação (ritmo), o movimento sonoro (altura), a intensidade da obra (dinâmica), diferenciar partes da canção - estrofe, refrão, estrofe - com movimentos e gestos distintos (forma), associar os timbres dos instrumentos ao movimento (timbre). O movimento, quer na forma de dança quer na forma de mímica, é uma forma prática e ativa de a criança compreender os conceitos musicais elementares e de os aplicar na prática performativa, seja ela instrumental ou vocal.

Segundo Findlay (1971, p. 3), ao apresentar os fundamentos da metodologia Dalcroze, "there are aural and visual rhythmic experiences, such as the sight of a plane flying high or the clop-clop of a horse's hoofs. If the child identifies himself further with what he has seen or heard, (...), the original rhythmic experience is deepened". Compreende-se que a importância que as vivências quotidianas têm no desenvolvimento das competências rítmicas das crianças, combinando neste caso o ritmo com o movimento, a vão ajudar a construir os seus conhecimentos musicais. É de destacar a importância que a relação música-movimento têm no desenvolvimento musical da criança e futuro aperfeiçoamento de aptidões musicais. 
A voz e a audição ativa. Para além da compreensão dos conceitos musicais através do movimento, a compreensão da música pela utilização da voz e pela audição ativa é igualmente importante. A voz é o instrumento principal do ser humano, uma vez que é através dela que se fala, canta, entoa. A utilização da voz pelo uso de canções traz consigo acoplada a aprendizagem do pré-solfejo: para Willems (1994, p. 101), "los ejercicios de presolfejo deben constituir el pasaje de la primera iniciación a la lectura musical”, compreendendo, entre outros domínios, a utilização de canções para introduzir no vocabulário musical a compreensão da altura de sons, quer por graus conjuntos quer por intervalos, sem que para tal, a criança se aperceba da literacia musical que vai construindo.

Contudo, nem todas as crianças gostam de comunicar musicalmente através da voz (canto), embora seja reconhecida como o instrumento de excelência para a aprendizagem musical. Segundo Wuytack e Palheiros (1992, p. 13) "é importante ensinar as crianças a interpretar canções, peças ou danças. Mas não menos importante é ensiná-las a saber ouvir música.”.

Neste seguimento, Paynter (2010, p. 35) afirma que "cada matiz de altura, duración, intensidad y articulación, (...), puede tener un efecto muy grande. El llegar a comprehender la morfología de los sonidos imitados, es un paso importante hacia la evolución y desarrollo de las ideas musicales”. A importância da compreensão, por parte da criança, do mundo sonoro que a rodeia é, para Paynter, algo que a ajuda a desenvolver determinadas aptidões musicais no futuro. Trabalhar com a criança a audição e a compreensão dos sons que a rodeiam, naturais ou não, leva-a a ter uma noção muito mais completa e detalhada da música, podendo vir a ouvir/usufruir como adolescente e adulto, transformando-a num ouvinte mais consciente e ativo nas suas escolhas e opções musicais. A aprendizagem faz-se via experiência, alargando depois pela compreensão e abstração à teoria.

O teatro musical. A representação teatral é, para a criança, a forma de recriar e de explorar o seu imaginário, brincando ao "faz de conta”, tão importante para o seu desenvolvimento cognitivo e emocional. A arte performativa da representação temu $m$ papel preponderante na maneira de exprimir ideias e emoções. Mills e Paynter (2008, p. 39) defendem que "creative music-theatre offers opportunities for a number of related arts experiences. It is also draws on the wide variety of imaginative talent to be found in any group of children”.

A recriação de personagens pela recriação ambientes sonoros faz com que cada um se possa expressar livremente, sem que para isso haja um guião pré-definido ou um roteiro a seguir.

Juntar a música à representação fará com que os elementos atrás referidos, movimento, voz e audição, sejam colocados palco. "Music-theatre is an art form itself. (...) It is, (..), the total integration of all those elements of human expression which we call art. That is: words, movement, music, (...) and (...) dimensional visual arts.” (Mills \& Paynter, 2008, pp. 39-40)
O jogo e a aprendizagem musical. Na antiga Grécia, a música era uma atividade vinculada a todas as manifestações sociais, culturais, e religiosas e o lúdico a era considerado como um fator determinante para o desenvolvimento integral do ser humano. $\mathrm{O}$ envolvimento, que o lúdico desperta por parte de quem é envolvido pela música, pelo jogo, pelo movimento, pela escuta atenta, estimula a autoestima, a autoconfiança, a relação saudável com os pares. Por outro lado, ativa a concentração nas tarefas em que se implicam, facilitando a organização do pensamento e desperta a motivação e propicia condições favoráveis à aprendizagem (Jaeger, s/d).

Interligando todos estes elementos fundamentais para a aprendizagem musical para e com crianças pequenas, chegamos ao ponto que mais interessa neste processo: para se introduzir e iniciar uma aprendizagem musical com crianças antes de se iniciar a prática instrumental, devemos brincar com a música, realizar um jogo para que competências musicais sejam construídas e consolidadas.

Para Swanwick (2000, p. 52), "si el dominio es el elemento del juego que nos orienta hacia los materiales artísticos y si la imitación se relaciona con el carácter expresivo o referencial del arte, el juego imaginativo nos centra en su estructura.”. Quer o autor com isto dizer que o jogo imaginativo é aquele que vai estruturar a base para a criação e conduzir a imaginação da criança por forma a recriar cenários e realidades.

Serve, então, o jogo para criar espaços de conhecimento e de partilha de experiências artísticas, neste caso musicais, nas quais se associam o movimento, a voz, a audição, a literatura, como matéria prima para a expressividade e desenvolvimento da sensibilidade artísticas.

\section{Os workshop como estratégia de ensino da música}

Por definição, entende-se por workshop uma apresentação ou demonstração onde o público é convidado a participar ativamente, com o objetivo de se aprender algo através da prática, pela troca de ideias, com a partilha de conhecimentos entre pares. Realiza-se em pequenos grupos para que a aprendizagem e construção de competências seja mais eficaz e frutífera.

Como foi anteriormente referido, a procura por outros espaços e atividades musicais para crianças pequenas é, cada vez mais, uma constante, não só por pais e encarregados de educação, mas também por escolas do ensino básico e jardins de infância que acreditam que a atividade musical e artística não se prende apenas à prática instrumental e à literacia musical.

Existe uma grande procura de workshop musicais, onde a expressão musical é o elemento fundamental dessas atividades, e a prática artístico-musical uma constante nestas atividades.

\section{Os workshop da Musicflat}

No ano letivo 2013-2014, a Musicflat planificou um workshop direcionado para crianças entre os 4 e os 10 anos, subdivididos em dois grupos - dos 4 aos 6 e dos 7 aos 10 anos, com a função de promover a instituição e 
igualmente levar às escolas e jardins de infância atividades musicais diferentes.

Em primeiro lugar, não é lida nem apresentada de maneira nenhuma a história a explorar, pois o dever do workshop passa por despertar o interesse literário nas crianças que, posteriormente, serão encaminhadas espontaneamente para a leitura da obra trabalhada.

Quanto workshop na componente musical em si, esta foi organizada em duas partes distintas, com atividades musicais distintas, consoante as faixas etárias dos participantes. O primeiro grupo, dos 4 aos 6 anos, abrange crianças do jardim de infância e do $1 .^{\circ}$ ano de escolaridade. $\mathrm{O}$ trabalho a desenvolver com este grupo incide na representação de partes da história pela aplicação na prática de conceitos musicais elementares (andamento, dinâmica, pulsação, altura dos sons) e caracterização das personagens com pequenos gestos e movimentos, explorando as suas particularidades e refletindo-as através da representação. Com regras a seguir, todos os participantes estiveram envolvidos ativamente no workshop, cumprindo com as regras apresentadas pelos dinamizadores por forma a que, neste jogo, todos possam estar presentes, possam participar de forma organizada, compreendendo todos os conceitos e conteúdos a explorar, sem se falar de literacia musical uma única vez. É pela compreensão prática, pelo movimento, canto, representação, audição ativa, que os conceitos musicais são apreendidos e compreendidos pelas crianças.

O segundo grupo, dos 7 aos 10 anos, experienciam outra componente musical: a prática instrumental sem conhecer ou falar de música. Apenas com musicogramas e as respetivas imagens dos instrumentos musicais utilizados, o ritmo é explorado com ostinatos rítmicos simples, no qual a duração de sons longos, curtos e respetivos silêncios são a base desta primeira parte. Num segundo momento, explorando a altura dos sons - agudo, médio e grave - a utilização de cores para identificar as diferentes notas musicais nas lâminas dos instrumentos de altura definida (comummente designados por instrumentos Orff), faz com que o grupo de crianças tenha a percepção da diferença de altura entre os sons da escala diatónica. Em todo o processo, os termos técnicos musicais não são referenciados como tal, apenas pela prática ativa, quer instrumental quer pela representação musical da história e das suas personagens.

Resultados obtidos. Os resultados obtidos durante as sessões realizadas, em escolas com contextos educativos bastante dispares, foram bastante positivos. A equipa de docentes que levou a cabo este workshop verificou que os alunos que não têm contato com o ensino da música formal, principalmente que não têm contato nem usufruem de ensino da música especializado, foram mais receptivos à atividade do que os que contatam com essa realidade de ensino. $\mathrm{O}$ facto de estarem mais abertos à diferença e a inovação faz com que a sua reflexão crítica, estética e criativa sejam mais ricas para si, como pessoas, e para quem está à frente destas atividades musicais.

Mais se verificou ao longo do ano letivo no qual se levou a cabo o workshop: o contato com uma história cujas personagens são reais, estão descritas e criadas por um autor, levaram a que as crianças, por livre iniciativa, quisessem ler não só a história apresentada, mas também outras obras literárias que despertem o interesse criativo, artístico e estético.

\section{Conclusões}

O ensino da música para crianças pequenas ainda carece de um forte investimento por parte de todos os envolvidos na educação e ensino das crianças. Não apenas escolas interessadas ou pais empenhados em dar aos seus educandos uma melhor e mais ampla formação artística e estética devem estar atentos à inovação e novidade, mas todos aqueles que se dizem envolvidos no processo de ensino e aprendizagem.

Muito embora se verifique, pela análise dos programas curriculares do $1 .^{\circ}$ ciclo do ensino básico ao longo dos últimos 40 anos, uma aposta por parte dos vários ministérios em implementar diferentes pedagogias e metodologias de ensino, o mesmo não se verifica nos últimos anos. Denota-se um forte investimento por parte dos pais e encarregados de educação no ensino especializado da música para os seus educandos, com o objetivo de ensinar a literacia musical e um instrumento musical, fora do âmbito escolar generalista, o que faz com que apenas alguns possam ter a oportunidade de estar em contato com a música, limitada à música performativa.

O contato com a música de uma forma mais abrangente, globalizante, que leva ao (re)conhecimento estético e crítico da criança, carece e merece uma maior atenção: a música como expressão artística e estética está cada vez mais entregue a pequenos investidores culturais e educacionais que, no terreno, verificam o quão limitadas artisticamente se encontram as nossas crianças, quão curtas são as suas visões quanto à exploração musical, teatral, literária, quão carentes se sentem de brincar e jogar com a criatividade e com a representação músico-teatral.

São desenvolvidas competências performativas pelo ensino da música mas ainda não se constroem competências estéticas e artísticas convenientemente por forma a se criarem públicos da cultura capazes de compreenderem uma obra artística num todo. Para tal, é urgente investir em workshops onde o jogo e a componente lúdica sejam a base de sustentação de uma educação musical e artística de qualidade para as crianças de hoje, adultos de amanhã.

\section{Referências}

Findlay, E. (1971). Rhythm and Movement: Applications of Dalcroze Eurhythmics. Van Nuys, CA: Summy-Birchard Inc.

Jaeger, W. (s/d). Paideia - a formação do homem grego. Lisboa: Editorial ASTER, LDA.

Mills, J., \& Paynter, J. (2008). Thinking and making. Oxford: Oxford.

Paynter, J. (2010). Sonido y estructura (1. ${ }^{\mathrm{a}}$ ed.). (H. Urquhart, Trad.) Madrid: Ediciones Akal.

Swanwick, K. (2000). Música, pensamiento y educación (2. ${ }^{\text {a }}$ ed.). (M. Olasagasti, Trad.) Madrid: Ediciones Morata. 
Tracana, M. G. (novembro de 2013). Perfil e funções do ensino da música nos ramos genérico e especializado no $1 .^{\circ}$ ciclo do ensino básico.Estudo de Caso Múltiplo. Braga: Universidade do Minho.

Willems, E. (1994). El valor humano de la educación musical (2. ${ }^{\mathrm{a}}$ ed.). Barcelona: Paidó Studio.

Wuytack, J., \& Boal Palheiros, G. (1992). Audição Musical Activa. Porto: Associação Wuytack de Pedagogia Musical. 